C. Xiao - A. Giacca - A. Carpentier - G. F. Lewis

\title{
Differential effects of monounsaturated, polyunsaturated and saturated fat ingestion on glucose-stimulated insulin secretion, sensitivity and clearance in overweight and obese, non-diabetic humans
}

Received: 3 November 2005 / Accepted: 1 February 2006 / Published online: 5 April 2006

(C) Springer-Verlag 2006

\begin{abstract}
Aims/hypothesis: Prolonged elevation of plasma specific fatty acids may exert differential effects on glucose-stimulated insulin secretion (GSIS), insulin sensitivity and clearance. Subjects and methods: We examined the effect of oral ingestion, at regular intervals for $24 \mathrm{~h}$, of an emulsion containing either predominantly monounsaturated (MUFA), polyunsaturated (PUFA) or saturated (SFA) fat or water (control) on GSIS, insulin sensitivity and insulin clearance in seven overweight or obese, nondiabetic humans. Four studies were conducted in each individual in random order, 4-6 weeks apart. Twentyfour hours after initiation of oral ingestion, subjects underwent a $2 \mathrm{~h}, 20 \mathrm{mmol} / \mathrm{l}$ hyperglycaemic clamp to assess GSIS, insulin sensitivity and insulin clearance. Results: Following oral ingestion of any of the three fat emulsions over $24 \mathrm{~h}$, plasma NEFAs were elevated by $\sim 1.5$ - to 2 -fold over the basal level. Ingestion of any of the three fat emulsions resulted in reduction in insulin clearance, and SFA ingestion reduced insulin sensitivity. PUFA ingestion was associated with an absolute reduction
\end{abstract}

Electronic Supplementary Material Supplementary material is available for this article at http://dx.doi.org/10.1007/s00125006-0211-x

C. Xiao · A. Giacca · G. F. Lewis

Departments of Medicine and Physiology,

University of Toronto,

Toronto, ON, Canada

A. Carpentier

Department of Medicine, Division of Endocrinology,

Sherbrooke University Hospital, Sherbrooke University,

Sherbrooke, QC, Canada

G. F. Lewis $(\square)$

Toronto General Hospital,

200 Elizabeth Street, Room EN 12-218,

Toronto, ON, Canada, M5G 2C4

e-mail: gary.lewis@uhn.on.ca

Tel.: +1-416-3404270

Fax: +1-416-3403314 in GSIS, whereas insulin secretion failed to compensate for insulin resistance in subjects who ingested SFA. Conclusions/interpretation: Oral ingestion of fats with differing degrees of saturation resulted in different effects on insulin secretion and action. PUFA ingestion resulted in an absolute reduction in insulin secretion and SFA ingestion induced insulin resistance. Failure of insulin secretion to compensate for insulin resistance implies impaired beta cell function in the SFA study.

Keywords Insulin clearance - Insulin resistance - Insulin secretion - Lipotoxicity $\cdot$ Non-esterified fatty acids .

NEFAs · Oral fat ingestion

Abbreviations $\mathrm{Cl}_{\mathrm{I}}$ : insulin clearance $\cdot \mathrm{G}_{\mathrm{inf}}$ : glucose infusion rate - GIP: glucose-dependent insulinotropic polypeptide · GLP-1: glucagon-like-peptide-1 · GSIS:

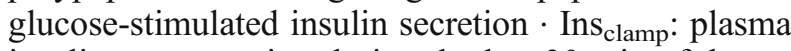
insulin concentration during the last $30 \mathrm{~min}$ of the hyperglycaemic clamp - ISR: insulin secretion rate · MUFA: monounsaturated fatty acid - PUFA: polyunsaturated fatty acid $\cdot$ SFA: saturated fatty acid

\section{Introduction}

Type 2 diabetes is characterised by defects in both insulin secretion and insulin action $[1,2]$, with a specific defect in glucose-stimulated insulin secretion (GSIS) early in the evolution of this disease [3,4]. While it has been generally accepted that fatty acids are essential for maintaining basal insulin secretion [5] and that an acute increase in plasma NEFAs enhances GSIS, prolonged elevation of plasma NEFAs has been shown to desensitise GSIS in humans in vivo (reviewed in [6,7]), particularly in predisposed individuals [8]. These findings are supported by a large body of in vitro work (reviewed in [9]).

The acute enhancement of GSIS by i.v. infusion of fat in rats depends on the type of NEFA, being proportional to the NEFA chain length and degree of saturation [10]. In humans, short-term oral ingestion of monounsaturated fat 
is more potent than ingestion of polyunsaturated and saturated fats in stimulating GSIS [11]. However, it remains unclear whether the saturation of fatty acids affects GSIS when levels are chronically elevated in vivo in humans. Much of the data from human studies to date come from infusion studies in which i.v. fat emulsions (Intralipid or Liposyn) and heparin were administered to provide an exogenous source of triglycerides and to stimulate lipoprotein lipase, respectively. The effect of saturated fatty acids (SFAs) or monounsaturated fatty acids (MUFAs) on beta cell function may differ from that of the largely polyunsaturated fatty acids (PUFAs) in these lipid emulsions. In addition, dietary NEFAs also stimulate intestinal secretion of incretins such as glucagon-like-peptide-1 (GLP-1) and glucose-dependent insulinotropic polypeptide (GIP), and can therefore indirectly potentiates GSIS [12]. Infusion of heparin-Intralipid to induce elevation of plasma NEFAs bypasses the gastrointestinal tract, which limits the use of this experimental system in examining the effect of dietary fatty acids on insulin action and sensitivity. For these reasons, and because solutions of MUFA and SFA are not currently available for safe i.v. administration to humans, in the present study we compared the effects of oral ingestion of SFA, PUFA and MUFA on insulin secretion and sensitivity.

The composition of plasma NEFAs was altered in the present study by the frequent ingestion of a hot, chocolateflavoured drink of fat emulsion that was virtually free of carbohydrate and protein, according to the method described recently by Beysen et al. [11]. In pilot studies we determined the maximal dose and duration of fat that could be administered in this fashion without causing nausea or diarrhoea. The objective of this study was to investigate the effects of the ingestion of various fatty acids, i.e. saturated, monounsaturated and polyunsaturated, on GSIS, insulin sensitivity and insulin clearance in humans. We elected to study overweight and obese, nondiabetic humans because we have previously shown that they are more susceptible to the impairing effect of chronically elevated fatty acids on GSIS than lean, insulin-sensitive individuals [13].

\section{Subjects and methods}

\section{Subjects}

Three overweight and four obese but otherwise healthy non-diabetic men participated in the study. Their demographic and clinical characteristics are shown in Table 1. Impaired glucose tolerance and diabetes mellitus was excluded by performing a standard $2 \mathrm{~h}$ oral glucose tolerance test prior to the study and assessing fasting plasma glucose concentrations at every study visit according to established diagnostic criteria [14]. Body weight remained stable in all individuals for the duration of the study. None of the participants was taking any medication or had any known systemic illness. Informed, written consent was obtained from all participants in accordance with the guidelines of the Human Subjects Review Committee of the University Health Network, University of Toronto.

\section{Experimental protocol}

Participants were admitted to the Endocrine/Metabolic Diagnostic Unit of the Toronto General Hospital at $07.00 \mathrm{~h}$ on four occasions, in randomised order, 4-6 weeks apart, after a $12 \mathrm{~h}$ overnight fast. On each occasion, participants ingested a hot, chocolate-flavoured drink consisting of either one of three fat emulsions (oil tests) or of water (control) every hour for the first $12 \mathrm{~h}$ followed by every $2 \mathrm{~h}$ for the remainder of the study, continuing through the clamp studies that began at $08.00 \mathrm{~h}$ on day 2 (i.e. the emulsion was ingested for a total of $30 \mathrm{~h}$ ). For the three oil tests, the hot drink at each ingestion time point consisted of the following ingredients: $13 \mathrm{~g}$ oil, $0.5 \mathrm{~g}$ emulsifier (monoglycerides), $1 \mathrm{~g}$ sweetener, $3 \mathrm{~g}$ cocoa powder and $100 \mathrm{ml}$ hot water. The macronutrient composition of this emulsion was $89.02 \%$ energy from fat, $9.24 \%$ from carbohydrate and $1.74 \%$ from protein $(136 \mathrm{kcal}$ or $571 \mathrm{~kJ}$ ingested at each time point). The emulsion was made up each day, kept warm in a Thermos flask and mixed by

Table 1 Characteristics of the subjects

\begin{tabular}{|c|c|c|c|c|c|c|c|c|c|c|c|c|}
\hline Subject & $\begin{array}{l}\text { Age } \\
\text { (years) }\end{array}$ & Sex & $\begin{array}{l}\text { Weight } \\
(\mathrm{kg})\end{array}$ & $\begin{array}{l}\text { Height } \\
(\mathrm{cm})\end{array}$ & $\begin{array}{l}\text { BMI } \\
\left(\mathrm{kg} / \mathrm{m}^{2}\right)\end{array}$ & $\begin{array}{l}\text { Waist } \\
(\mathrm{cm})\end{array}$ & $\begin{array}{l}\text { Hip } \\
(\mathrm{cm})\end{array}$ & WHR & $\begin{array}{l}\text { Fasting plasma } \\
\text { glucose }(\mathrm{mmol} / \mathrm{l})\end{array}$ & $\begin{array}{l}\text { Fasting plasma } \\
\text { insulin }(\mathrm{pmol} / \mathrm{l})\end{array}$ & $\begin{array}{l}\text { Fasting plasma } \\
\text { NEFA }(\mathrm{mmol} / \mathrm{l})\end{array}$ & $\begin{array}{l}\text { Fasting plasma } \\
\text { C-peptide } \\
(\mathrm{nmol} / \mathrm{l})\end{array}$ \\
\hline 1 & 55 & M & 86.7 & 176.0 & 27.9 & 103.5 & 108.3 & 0.95 & 4.8 & 67 & 0.33 & 0.45 \\
\hline 2 & 49 & M & 87.9 & 160.2 & 34.3 & 104.0 & 113.3 & 0.91 & 5.5 & 74 & 0.92 & 0.26 \\
\hline 3 & 37 & M & 112.2 & 186.0 & 32.5 & 113.3 & 122.3 & 0.92 & 4.8 & 95 & 0.40 & 0.54 \\
\hline 4 & 51 & M & 90.5 & 180.0 & 27.9 & 94.0 & 106.5 & 0.88 & 5.5 & 116 & 0.26 & 0.55 \\
\hline 5 & 41 & M & 127.3 & 180.0 & 39.3 & 129.5 & 125.5 & 1.03 & 5.8 & 143 & 0.40 & 1.16 \\
\hline 6 & 34 & M & 98.7 & 178.0 & 31.5 & 106.5 & 112.0 & 0.94 & 5.2 & 114 & 0.44 & 1.19 \\
\hline 7 & 41 & M & 91.0 & 175.0 & 29.7 & 106.3 & 110.3 & 0.96 & 5.5 & 76 & 0.46 & 0.91 \\
\hline $\begin{array}{l}\text { Mean } \\
\text { (SE) }\end{array}$ & $\begin{array}{l}44 \\
(2.6)\end{array}$ & - & $\begin{array}{c}99.2 \\
(5.1)\end{array}$ & $\begin{array}{r}176.5 \\
(2.7)\end{array}$ & $\begin{array}{l}31.8 \\
(1.3)\end{array}$ & $\begin{array}{r}108.1 \\
(3.7)\end{array}$ & $\begin{array}{r}114.0 \\
(2.4)\end{array}$ & $\begin{array}{c}0.94 \\
(0.02)\end{array}$ & $\begin{array}{c}5.3 \\
(0.1)\end{array}$ & $\begin{array}{r}98 \\
(11)\end{array}$ & $\begin{array}{c}0.46 \\
(0.08)\end{array}$ & $\begin{array}{c}0.72 \\
(0.14)\end{array}$ \\
\hline
\end{tabular}


shaking prior to ingestion. The three oils used in the study were olive oil $(78 \%$ monounsaturates, $8 \%$ polyunsaturates and $14 \%$ saturates; $71 \%$ oleic acid, $13 \%$ palmitic acid and $10 \%$ linoleic acid; referred to as MUFA), palm oil (50\% saturates, $40 \%$ monounsaturates and $10 \%$ polyunsaturates; $48 \%$ palmitic acid, $35 \%$ oleic and $8 \%$ linoleic acid; SFA) and safflower oil (78\% polyunsaturates, $13 \%$ monounsaturates and $9 \%$ saturates; $74 \%$ linoleic acid, $12 \%$ oleic acid and $6 \%$ palmitic acid; PUFA). We acknowledge that palm oil contains not only SFA but also a fair amount of MUFA. In the control test, oil was replaced with water. Subjects were not permitted to eat for the duration of the experiments but were allowed free access to water. Blood samples were drawn at $08.00,12.00$ and $16.00 \mathrm{~h}$ on day 1 and $08.00 \mathrm{~h}$ on day 2 for monitoring blood glucose, insulin, triglycerides, NEFA, C-peptide, GLP-1 and GIP. Ingestion of the emulsion began after the $08.00 \mathrm{~h}$ sample had been drawn on day 1.

Assessment of glucose-stimulated insulin secretion, insulin sensitivity and insulin clearance

On day 2, an i.v. catheter was placed in the superficial vein of one forearm for infusion of glucose and insulin and another catheter was placed in the other forearm for blood sampling. The arm in which the sampling catheter was placed was maintained in a heating blanket $\left(\sim 65^{\circ} \mathrm{C}\right)$ to 'arterialise' venous blood. At approximately $08.00 \mathrm{~h}$ a $2 \mathrm{~h}$, $20 \mathrm{mmol} / \mathrm{l}$ hyperglycaemic clamp study was conducted as previously described [15]. Prior to starting the hyperglycaemic clamp, blood samples were drawn at $10 \mathrm{~min}$ intervals for analysis of glucose, insulin, triglycerides, NEFAs and C-peptide during a $30 \mathrm{~min}$ basal period before glucose infusion. Samples for NEFA and triglyceride analysis were collected into chilled EDTA-containing tubes on ice containing $30 \mu \mathrm{g} / \mathrm{ml}$ of the lipase inhibitor tetrahydrolipstatin (Orlistat; Hoffman La Roche, Mississauga, ON, Canada), to prevent ongoing in vitro lipolysis of the samples [16]. The subjects then received a primed i.v. infusion of $20 \%$ dextrose for $2 \mathrm{~h}$ to rapidly achieve and then maintain hyperglycaemia of $20 \mathrm{mmol} / \mathrm{l}$, as previously described [17]. Blood samples were drawn every $5 \mathrm{~min}$ during the remainder of the clamp for glucose assay at the bedside. Samples for insulin, NEFAs and C-peptide were obtained 30 and $60 \mathrm{~min}$ into the clamp and every $5 \mathrm{~min}$ during the last $30 \mathrm{~min}$ of the clamp.

\section{Laboratory methods (see Electronic Supplementary Material)}

\section{Insulin secretion rate}

Insulin secretion rate (ISR) was calculated from peripheral venous plasma $\mathrm{C}$-peptide levels by deconvolution using a two-compartment mathematical model with standard parameters for C-peptide distribution and metabolism as previously described [18].

\section{Insulin clearance}

Insulin clearance $\left(\mathrm{Cl}_{\mathrm{I}}\right)$ was calculated as $\mathrm{Cl}_{\mathrm{I}}=\mathrm{ISR} / \mathrm{Ins}_{\text {clamp}}$, where $\mathrm{Ins}_{\text {clamp }}$ is plasma insulin concentration during the last $30 \mathrm{~min}$ of the hyperglycaemic clamp.

\section{Estimation of insulin sensitivity}

Since insulin levels during the last $30 \mathrm{~min}$ of the hyperglycaemic clamp varied significantly among treatments, it was assumed that, in the absence of changes in insulin sensitivity among treatments (null hypothesis), glucose infusion rates would exhibit an approximately linear relationship with clamp insulin levels, within the restricted range of insulin levels (from 1,000 to 2,000 pmol/l) observed in this protocol. The glucose infusion rate $\left(G_{\text {inf }}\right)$ was plotted against clamp insulin level $\left(\operatorname{Ins}_{\text {clamp }}\right)$ to illustrate the effects of differences in fat ingestion on whole-body insulin action.

\section{Statistical analysis}

The data were expressed as mean \pm SEM. Levels of glucose, insulin, triglycerides, NEFA, C-peptide, specific fatty acids, GLP-1, GIP, cortisol and $\beta$-hydroxybutyrate at time intervals during the first $24 \mathrm{~h}$ were analysed by threeway ANOVA (independent variables: treatment, time and subject, with interaction between treatment and time) with post hoc Tukey's $t$ - test for multiple comparisons of means. The analysis was repeated for each time point. The comparison of plasma glucose, insulin and C-peptide concentrations, $G_{\text {inf }}$, ISR and $\mathrm{Cl}_{\mathrm{I}}$ during the steady-state period (from 90 to $120 \mathrm{~min}$ of the hyperglycaemic clamp) was assessed by two-way ANOVA (independent variables: treatment and subject), with post hoc Tukey's $t$-test for multiple comparisons of means to detect significant differences between treatments. A $p$ value of $<0.05$ was considered significant. Statistical analyses were performed using SAS software, version 8.0 (SAS Institute, Cary, NC, USA).

\section{Results}

Plasma glucose, insulin, triglycerides, NEFA, C-peptide, GLP-1 and GIP during fasting and ingestion of the emulsion for the first $24 \mathrm{~h}$ of the study

All parameters were similar for all four studies prior to ingestion of the chocolate-flavoured emulsion (following a $12 \mathrm{~h}$ overnight fast, at time $08.00 \mathrm{~h}$ on day 1) (Tables 2 and 3 ). At $24 \mathrm{~h}$ after initiation of the oil ingestion (at time $08.00 \mathrm{~h}$ on day 2), plasma glucose remained unchanged from baseline within each treatment and similar between the four treatments. Plasma insulin in the control group decreased significantly $(p<0.05)$ from baseline but there was no significant change in the other treatment groups. There were no significant differences in C-peptide con- 
Table 2 Plasma glucose, insulin and C-peptide levels during fasting and oral ingestion of control solution or SFA, MUFA or PUFA oil emulsion

\begin{tabular}{|c|c|c|c|c|c|c|c|c|c|c|c|c|}
\hline & \multicolumn{4}{|c|}{ Glucose $(\mathrm{mmol} / \mathrm{l})$} & \multicolumn{4}{|c|}{ Insulin (pmol/1) } & \multicolumn{4}{|c|}{ C-peptide (nmol/l) } \\
\hline & Control & SFA & MUFA & PUFA & Control & SFA & MUFA & PUFA & Control & SFA & MUFA & PUFA \\
\hline \multicolumn{13}{|l|}{ Day 1} \\
\hline 08.00 & $5.3 \pm 0.2$ & $5.2 \pm 0.2$ & $5.3 \pm 0.2$ & $5.4 \pm 0.3$ & $93 \pm 10$ & $108 \pm 22$ & $81 \pm 11$ & $108 \pm 27$ & $0.88 \pm 0.17$ & $0.69 \pm 0.18$ & $0.61 \pm 0.11$ & $0.58 \pm 0.14$ \\
\hline 12.00 & $4.8 \pm 0.2$ & $4.8 \pm 0.3$ & $5.2 \pm 0.1$ & $5.1 \pm 0.2$ & $60 \pm 18$ & $120 \pm 30$ & $68 \pm 8$ & $87 \pm 19$ & $0.70 \pm 0.19$ & $0.66 \pm 0.12$ & $0.56 \pm 0.11$ & $0.58 \pm 0.13$ \\
\hline 16.00 & $4.8 \pm 0.1$ & $4.8 \pm 0.3$ & $4.6 \pm 0.1$ & $4.7 \pm 0.1$ & $63 \pm 10$ & $83 \pm 25$ & $60 \pm 14$ & $80 \pm 22$ & $0.59 \pm 0.11$ & $0.81 \pm 0.13$ & $0.50 \pm 0.11$ & $0.61 \pm 0.16$ \\
\hline \multicolumn{13}{|l|}{ Day 2} \\
\hline 08.00 & $5.3 \pm 0.2$ & $4.9 \pm 0.2$ & $5.0 \pm 0.1$ & $5.2 \pm 0.2$ & $62 \pm 9^{\mathrm{a}}$ & $81 \pm 16$ & $82 \pm 17$ & $73 \pm 22$ & $0.61 \pm 0.17$ & $0.61 \pm 0.16$ & $0.53 \pm 0.12$ & $0.59 \pm 0.16$ \\
\hline
\end{tabular}

Data are means \pm SE; $n=7$ subjects

${ }^{\mathrm{a}} p<0.05 \mathrm{vs} 08.00 \mathrm{~h}$ at day 1

There were no significant differences compared with control at any of the time points

centration between the treatment groups. Oral ingestion of SFA, MUFA and PUFA for $24 \mathrm{~h}$ significantly elevated plasma NEFAs 1.8-, 1.9- and 1.7-fold, respectively $(p<0.05$ for all fat ingestions). The elevation of NEFA with PUFA had a significantly $(p<0.05)$ different timecourse from that with MUFA and SFA. Ingestion of PUFA, but not of MUFA or SFA, led to a significant elevation of plasma NEFAs from the basal level as early as $16.00 \mathrm{~h}$ $(p<0.05)$ (i.e. $8 \mathrm{~h}$ after starting ingestion of the emulsion). In addition, there was a significant interaction between time and treatment with regard to plasma triglyceride concentrations. Triglycerides increased after $8 \mathrm{~h}$ of ingestion of MUFA and after $4 \mathrm{~h}$ of PUFA ingestion and remained elevated for the remainder of the $24 \mathrm{~h}$ period $(p<0.05)$. Triglycerides in the SFA, MUFA and PUFA groups were higher than in the control group at $16.00 \mathrm{~h}$ $(p<0.05)$ and those in SFA and MUFA groups remained higher than that in the control group after $24 \mathrm{~h}$ of fat ingestion $(p<0.05)$.

Plasma NEFA composition after $24 \mathrm{~h}$ of ingestion of the emulsion is shown in Fig. 1. We measured stearic (18:00) and palmitic (16:00) acids as the predominant circulating SFA, oleic acid (18:01) as the predominant MUFA, and linoleic acid (18:02) as the predominant PUFA. Together, these fatty acids constitute at least $90 \%$ of all circulating fatty acids [19]. Oral ingestion of different fats modified the concentration of specific fatty acids in the plasma. Although the difference was not statistically significant, SFA ingestion increased plasma SFA (palmitic acid plus stearic acid) by $36 \%$ over that in the control group, with an increase in palmitic acid of $40 \%$ and in stearic acid of $28 \%$. MUFA ingestion significantly increased plasma oleic acid 2.5 -fold from the control level $(p<0.001)$. Plasma oleic acid in the MUFA study was also significantly higher than that in the PUFA study $(p<0.005)$. In the PUFA study, linoleic acid increased 2.5-fold from the control level and was higher than that in the MUFA study $(p<0.05)$.

GLP-1 and GIP levels during the $24 \mathrm{~h}$ ingestion period, prior to starting the clamp studies, were not different between studies (not illustrated). During this $24 \mathrm{~h}$ period the active GLP-1 levels in plasma did not increase from baseline in any of the studies $(10.96 \pm 1.72 \mathrm{pmol} / 1$ for control, $9.86 \pm 4.09 \mathrm{pmol} / 1$ for SFA, $10.56 \pm 3.53 \mathrm{pmol} / 1$ for MUFA and $10.30 \pm 5.50 \mathrm{pmol} / \mathrm{l}$ for PUFA). Plasma GIP levels did not increase from baseline in the control group and even decreased slightly during the $24 \mathrm{~h}$ period $(32.33 \pm$ $11.68 \mathrm{ng} / \mathrm{l}$ at $24 \mathrm{~h}$ versus $43.17 \pm 7.70 \mathrm{ng} / \mathrm{l}$ at baseline). Fat ingestion for $24 \mathrm{~h}$ resulted in increased levels of GIP in all treatment groups $(74.14 \pm 10.75 \mathrm{ng} / \mathrm{l}$ at $24 \mathrm{~h}$ versus $40.00 \pm$ $7.52 \mathrm{ng} / \mathrm{l}$ at baseline for SFA, $98.00 \pm 13.14$ vs $50.86 \pm$ $7.35 \mathrm{ng} / \mathrm{l}$ for MUFA, and $84.57 \pm 16.68$ vs $51.50 \pm 15.14 \mathrm{ng} / 1$ for PUFA; $p<0.05$ ). GIP levels in all oil tests after $24 \mathrm{~h}$ of ingestion were higher than those in the control group $(p<0.01$ for SFA and MUFA, $p<0.05$ for PUFA).

Serum cortisol levels (not illustrated) were not different between treatment protocols prior to fat ingestion (330.4, $347.5,364.5$ and $337.4 \mathrm{nmol} / 1$ for control, SFA, MUFA and PUFA, respectively) and $24 \mathrm{~h}$ after fat ingestion (334.1,

Table 3 Plasma NEFA and triglycerides during fasting and oral ingestion of control solution or SFA, MUFA or PUFA oil emulsion

\begin{tabular}{|c|c|c|c|c|c|c|c|c|}
\hline & \multicolumn{4}{|c|}{ NEFAs (mmol/1) } & \multicolumn{4}{|c|}{ Triglycerides $(\mathrm{mmol} / \mathrm{l})$} \\
\hline & Control & SFA & MUFA & PUFA & Control & SFA & MUFA & PUFA \\
\hline \multicolumn{9}{|l|}{ Day 1} \\
\hline 12.00 & $0.54 \pm 0.17$ & $0.41 \pm 0.06$ & $0.46 \pm 0.09$ & $0.51 \pm 0.09$ & $1.43 \pm 0.40$ & $1.87 \pm 0.56$ & $1.52 \pm 0.20$ & $1.78 \pm 0.30^{\mathrm{a}}$ \\
\hline 16.00 & $0.57 \pm 0.10$ & $0.43 \pm 0.05$ & $0.62 \pm 0.13$ & $0.77 \pm 0.15^{\mathrm{a}}$ & $1.35 \pm 0.20$ & $1.33 \pm 0.22$ & $2.00 \pm 0.26^{\mathrm{a}, \mathrm{b}}$ & $1.84 \pm 0.13^{\mathrm{a}, \mathrm{b}}$ \\
\hline
\end{tabular}

Data are means \pm SE; $n=7$ subjects

${ }^{\mathrm{a}} p<0.05$ vs $08.00 \mathrm{~h}$ at day $1 ;{ }^{\mathrm{b}} p<0.05$ vs control 


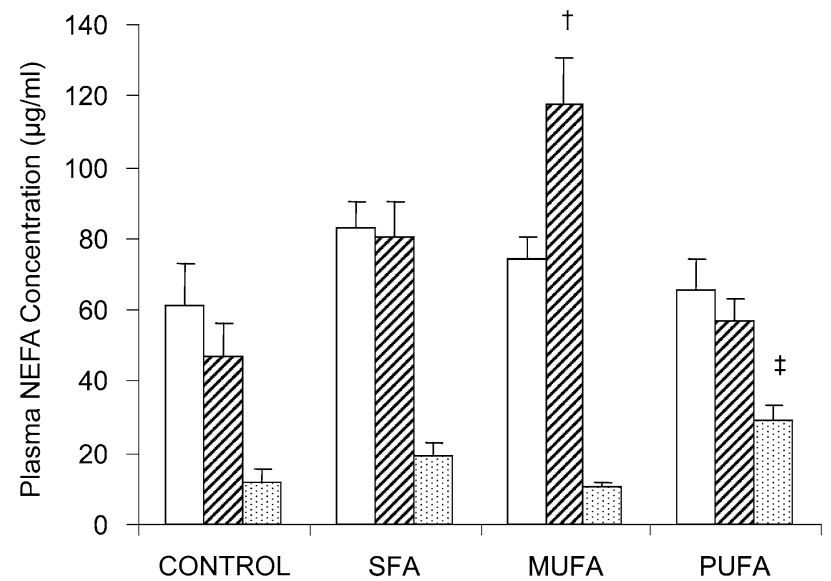

Fig. 1 Plasma fatty acid composition after $24 \mathrm{~h}$ of oil ingestion in seven subjects who participated in four studies each: control (control study), SFA (saturated fat ingestion), MUFA (monounsaturated fat ingestion) and PUFA (polyunsaturated fat ingestion). Compared with the control study, SFA ingestion tended to increase plasma palmitic acid+stearic acid (16:00+18:00; empty boxes) by $36 \%$, MUFA ingestion increased plasma oleic acid (18:01; hatched boxes) 2.5 -fold $\left({ }^{\top} p<0.001\right)$, and PUFA ingestion increased plasma linoleic acid (18:02; dotted boxes) 2.5 -fold $\left.{ }^{*} p<0.05\right)$
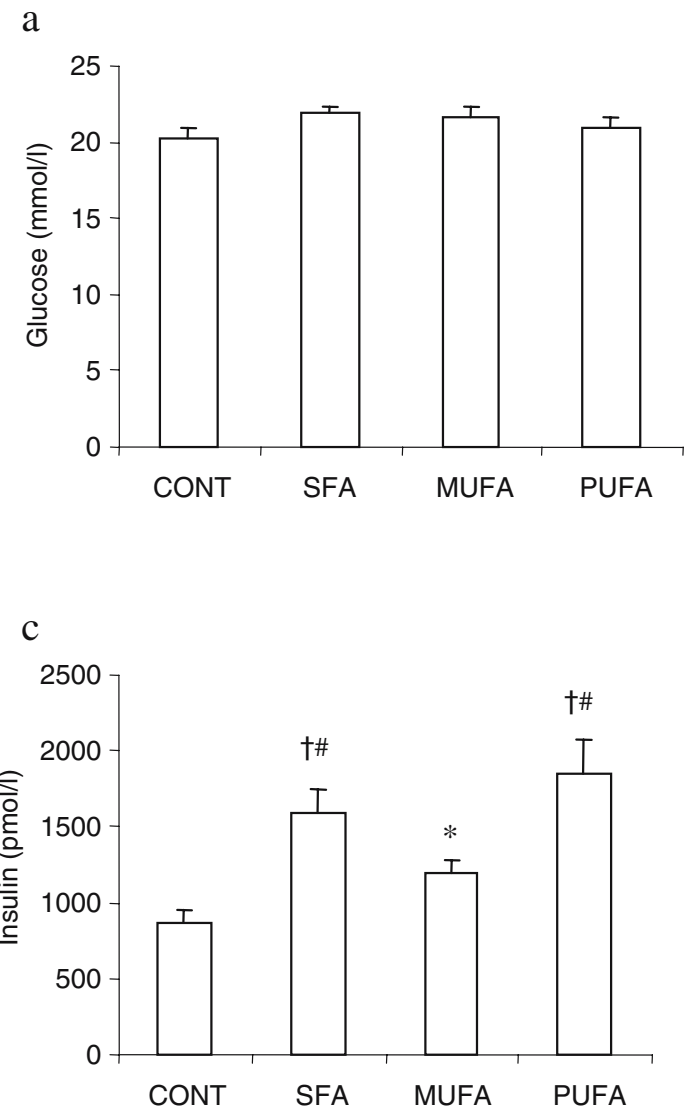

Fig. 2 Glucose (a), glucose infusion $\left(G_{\text {inf }}\right)$ rates (b), insulin (c) and C-peptide (d) during the last $30 \mathrm{~min}$ of the $20-\mathrm{mmol} / 1$ hyperglycaemic clamp. During the last $30 \mathrm{~min}$ of the clamp, glucose was similar between studies by design. $G_{\text {inf }}$ was higher in the PUFA study than in the control (CONT) $\left({ }^{*} p<0.05\right)$ and SFA $\left({ }^{\dagger} p<0.001\right)$
328.6, 363.5 and $374.3 \mathrm{nmol} / 1$ for control, SFA, MUFA and PUFA, respectively). Ketones were not detected in plasma either at baseline or $24 \mathrm{~h}$ after ingestion of the emulsion in any of the four study protocols.

Plasma glucose, glucose infusion rates, insulin and C-peptide during the $20 \mathrm{mmol} / \mathrm{l}$ hyperglycaemic clamp

By design, plasma glucose levels during the hyperglycaemic clamp were similar between treatments and were maintained at $\sim 20 \mathrm{mmol} / \mathrm{l}$ during the last $30 \mathrm{~min}$ of the clamp (Fig. 2a). To maintain the targeted $20 \mathrm{mmol} / \mathrm{l}$ hyperglycaemic level, higher $G_{\text {inf }}$ was required for the PUFA group compared with control $(p<0.05)$ and SFA $(p<0.001)$ (Fig. 2b). Mean insulin levels in all oil treatments were higher than in the control group during the last $30 \mathrm{~min}$ of the clamp (Fig. 2c). Mean insulin levels were 1.8-, 1.4- and 2.1-fold higher in the SFA $(p<0.001)$, MUFA $(p<0.05)$ and PUFA $(p<0.001)$ groups, respectively, than in the control group. Insulin was higher in the SFA and PUFA groups than in the MUFA group $(p<0.05)$. C-peptide concentrations in the SFA and MUFA groups were not

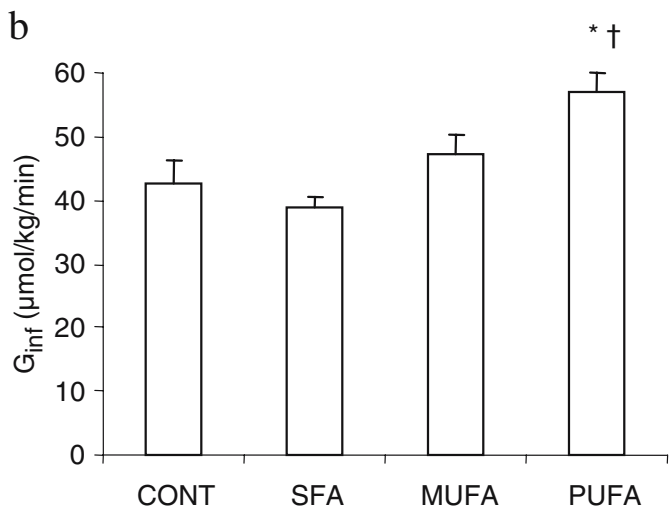

d

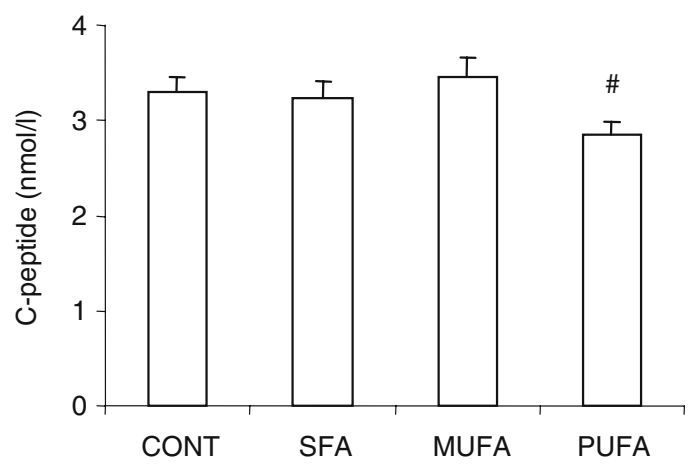

studies. Insulin was higher in all three oil groups compared with control $\left({ }^{*} p<0.05\right.$ for MUFA; ${ }^{\dagger} p<0.001$ for SFA and PUFA) and insulin was higher in the SFA and PUFA studies than in the MUFA study ( $\# p<0.05$ ). C-peptide was lower in the PUFA groups than in the other two oil treatment groups ( $\# p<0.05$ ) 
significantly different from that in the control group, while C-peptide level in the PUFA group was 14\% lower than that in the control group $(p<0.05)$ (Fig. $2 d)$.

Insulin secretion rate, insulin sensitivity and insulin clearance

The calculated insulin secretion rate during the last $30 \mathrm{~min}$ of the hyperglycaemic clamp was lower in the PUFA group $(p<0.05)$ than in the other three treatment protocols (Fig. 3a). Insulin secretion rates in the SFA and MUFA groups were similar to that in the control group. The relationship between $G_{\text {inf }}\left(\mu \mathrm{mol} \mathrm{kg} \mathrm{kin}^{-1}\right)$ and clamp insulin level (pmol/l) was linear, yielding a straight regression line $\quad\left(G_{\text {inf }}=0.0146 \times \operatorname{Ins}_{\text {clamp }}+29.951\right.$, $\left.r^{2}=0.9999, p<0.05\right)$ when the data of the SFA treatment were excluded (Fig. 3b), but was not significant $\left(G_{\text {inf }}=0.009 \times\right.$ Ins $\left._{\text {clamp }}+33.957, r^{2}=0.2513\right)$ when the data of the SFA treatment were included. This indicates that, in the control, MUFA and PUFA groups, $G_{\text {inf }} / \mathrm{Ins}_{\text {clamp }}$ (an index of insulin sensitivity) was similar (constant slope), but this ratio was reduced with SFA, consistent with insulin resistance in the SFA study. $\mathrm{Cl}_{\mathrm{I}}$ was significantly

a

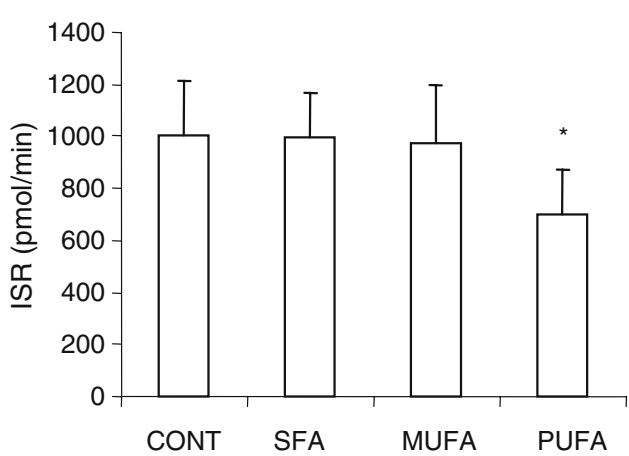

C

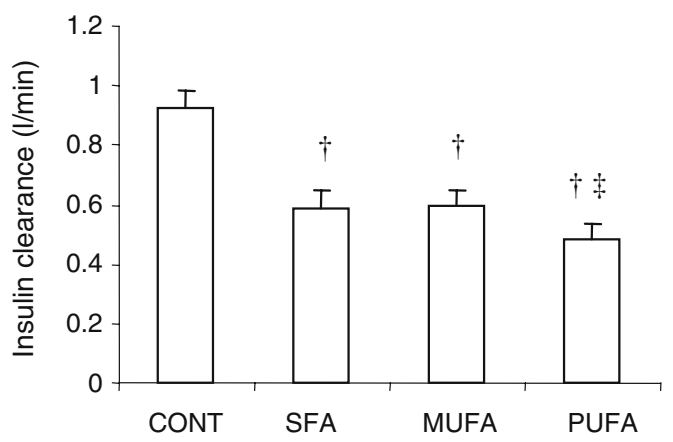

Fig. 3 a Bar graph to show ISR. ISR was significantly impaired in the PUFA group $\left({ }^{*} p<0.05\right.$ vs control [CONT], SFA and MUFA). b Insulin sensitivity was impaired in the SFA group. There was a significant linear relationship between glucose infusion rate $\left(G_{\text {inf }}\right)$ and plasma insulin concentration during the last $30 \mathrm{~min}$ of the hyperglycaemic clamp (Ins clamp$) \quad\left(G_{\text {inf }}=0.0146 \times\right.$ Ins $_{\text {clamp }}+29.951, \quad r^{2}=0.9999$, $p<0.05)$ when the data of the SFA treatment were excluded, indicating a constant $G_{\text {inf }} /$ Ins $_{\text {clamp }}$ slope. The linear relationship was not reduced in all three oil ingestion studies compared with the control group $(p<0.001) . \mathrm{Cl}_{\mathrm{I}}$ in the PUFA study was significantly lower than in the other two oil ingestion studies $(p<0.001)$ (Fig. 3c).

\section{Discussion}

In the present study we demonstrated that, in overweight and obese non-diabetic humans, frequent oral ingestion of fats containing NEFAs with varying degrees of saturation, i.e. MUFA, PUFA or SFA, resulted in differential effects on insulin secretion, action and clearance. Ingestion of PUFA resulted in an absolute reduction in GSIS whereas SFA ingestion induced insulin resistance. Insulin clearance was reduced with ingestion of all fats; however, the reduction was greatest with PUFA. To our knowledge, no previous studies have directly examined the effects of prolonged oral ingestion of fats on GSIS and the action and clearance of insulin in humans.

Previous studies, including our own, that have examined the effect of prolonged elevation of NEFAs on beta cell function and whole-body insulin sensitivity in humans have been performed by infusing a triglyceride emulsion,

b

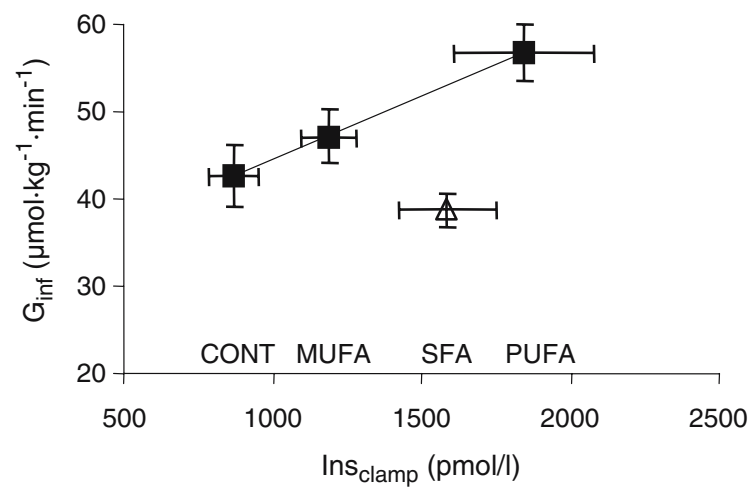

significant $\left(G_{\text {inf }}=0.009 \times\right.$ Ins $\left._{\text {clamp }}+33.957, r^{2}=0.2513\right)$ when the SFA data were included. The solid line was drawn without SFA data. c Insulin clearance calculated from the last $30 \mathrm{~min}$ of the $20-\mathrm{mmol} / 1$ hyperglycaemic clamp was significantly impaired with ingestion of all three fats. The impairment was greater with PUFA than with SFA or MUFA ( ${ }^{\dagger} p<0.001$ vs control, ${ }^{\dagger} p<0.001$ vs SFA and MUFA) 
such as Intralipid, together with a continuous low-dose heparin infusion [13, 15, 20-23]. Because we specifically wished to compare the effect of SFA, MUFA and PUFA on insulin secretion, sensitivity and clearance in the present study and for the other reasons outlined in the Introduction, we turned to a method of oral fat ingestion recently described by Beysen et al. [11], in which the authors examined the stimulatory effects of an acute elevation of various fatty acids on insulin secretion. This method has not been used previously to examine the effects of a prolonged elevation of NEFA. The protocol used for this study required the patient to ingest the emulsion every hour during the first $12 \mathrm{~h}$ and 2-hourly for the second $12 \mathrm{~h}$ of the $24 \mathrm{~h}$ ingestion period. The disturbed sleep pattern of subjects could have induced a certain degree of stress and it is well known that stress can affect glucose metabolism. Serum cortisol levels were assessed in all subjects at 0 and $24 \mathrm{~h}$, and there were no differences between the four treatment protocols. Since each hourly aliquot of the emulsion contained $136 \mathrm{kcal}$, the total energy intake during $24 \mathrm{~h}$ of oil ingestion for each subject was 2,448 kcal (i.e. $136 \times 18=2,448 \mathrm{kcal}$ ), which is slightly above the calculated resting metabolic rates $(2,016 \pm 100.8 \mathrm{kcal})$ using the Harris-Benedict equation [24]. Caloric intake during the control study was less than that during the three oil ingestion studies. Because the control study was performed with the subjects ingesting the same volume of hot chocolate-flavoured drink (with water rather than oil added), at the same time intervals as the three oil ingestion studies, the amount of carbohydrate ingested in all studies was sufficient to prevent frank ketosis.

In the present study, PUFA ingestion was the only fat ingestion associated with a significant reduction in absolute GSIS. We have previously shown that infusion for $24-48 \mathrm{~h}$ of heparin-Intralipid, which contains mainly PUFA, impairs GSIS in humans [13, 15, 23, 25]. The Intralipid and heparin infusion protocol results in a 4-, 2- and 1.7-fold increase in linoleate, oleate and palmitate levels, respectively, at fasting plasma insulin concentration [26]. In rats, the acute effect of elevated NEFAs in enhancing beta cell function is greatest with SFA, intermediate with MUFA and least with PUFA $[10,27]$. In a recent study in humans, short-term elevation of plasma NEFAs by oral fat ingestion augmented GSIS with the order of MUFA $>$ PUFA $>$ SFA [11]. It is less clear whether the prolonged effect of NEFAs in impairing beta cell function also depends on the degree of unsaturation of the fatty acids, and previous studies conducted in a variety of species and using different experimental protocols have shown highly variable results. Data in isolated rat islets [28] and beta cell lines [29] indicate that prolonged exposure to oleate (MUFA) might impair GSIS slightly more than exposure to linoleate $(n-6$ PUFA) or palmitate (SFA). In rats, prolonged i.v. infusion of MUFA had a greater impairing effect on GSIS than $n-6$ PUFA [30]. Interestingly, in the same rat model, i.v. infusion of SFA did not impair GSIS [31]. In this last study, the effects of a PUFA-rich versus a SFA-rich diet were also compared: the PUFA-rich diet impaired insulin secretion, whereas the diet rich in SFA did not, which is in accordance with the present study using oral fat ingestion in humans. The mechanisms whereby fatty acids differing in saturation might lead to different effects on beta cell function remain unclear. It was suggested that unsaturated but not saturated fatty acids can activate peroxisome proliferator-activated receptor $\gamma(\operatorname{PPAR} \gamma)$ [32-34]. PPAR $\gamma$ upregulates uncoupling protein 2 (UCP2), the overexpression of which impairs GSIS [35]. It is also possible that, compared with saturated fatty acids, unsaturated fatty acids induce a greater degree of oxidative stress, a process that is suggested to underlie glucolipotoxicity [36, 37].

In the present study, SFA ingestion induced insulin resistance. Our results are in line with those of previous studies showing that the impairing effect of high-fat diets on insulin action is proportional to the degree of saturation of fatty acids, SFA inducing the greatest insulin resistance, followed by MUFA and $n$-6 PUFA, whereas $n-3$ PUFA may have protective effects [38-40]. We cannot with confidence exclude impairment of insulin sensitivity with the ingestion of PUFA or MUFA, however, because insulin sensitivity was not determined using a gold standard in vivo experimental technique, such as the euglycaemichyperinsulinemic clamp.

The fact that only PUFA ingestion resulted in an absolute reduction in insulin secretion in this study may lead one to conclude that only PUFA impairs beta cell function. While we cannot exclude a greater impairing effect of PUFA on beta cell function, it should be considered that with SFA insulin secretion failed to increase to compensate for insulin resistance. In individuals with normal beta cell function, a decline in insulin sensitivity is followed by a compensatory increase in insulin secretion to maintain the ability of the body to dispose of glucose [41]. The fact that ISR was not increased to compensate for the decreased insulin action suggests that there was also impairment in beta cell function in the SFA study, either primary or secondary to the decrease in insulin clearance (see below).

GLP-1 and GIP are two incretins that are secreted by the endocrine L-cells and K-cells, respectively, and potentiate GSIS [42]. MUFA, but not SFA, have been shown to stimulate GLP-1 secretion [43]. Stimulated GLP-1 secretion was not observed in the present study. It is possible that the short half-life of GLP-1 masked the stimulatory effects of ingested fats on GLP-1 secretion. It has also been suggested that fats stimulate GLP-1 secretion only when the total energy intake of an oral fat load exceeds an energy threshold of $400 \mathrm{kcal}$ [44]. In the present study the relatively small amounts of fat ingested in each drink would have been below this threshold, providing one possible explanation for the absence of GLP-1 stimulation. Nevertheless, elevated total plasma GIP suggests the presence of incretin effects on potentiating GSIS.

We have shown previously that elevation of NEFAs induced by intravenous infusion of Intralipid for 24-48 h impairs insulin clearance in humans [13] and in dogs at both high and low insulin concentrations [45]. In the present study, ingestion of any of the fats decreased insulin clearance, which explains the elevated plasma insulin concentrations in the fat ingestion studies. A reduction in 
insulin clearance might represent a compensatory mechanism for peripheral insulin resistance or impaired insulin secretion, by providing greater escape of insulin from firstpass hepatic degradation, thereby contributing to peripheral hyperinsulinaemia or preventing peripheral insulin deficiency, respectively [46]. The mechanism for this apparently coordinated reduction in insulin clearance when the action or secretion of insulin is reduced is not known at present. Because reduced insulin clearance can maintain glucose homeostasis in the face of impairment in insulin secretion, it is possible that the reduction in insulin clearance compensates for an impairment of beta cell function. Alternatively, the reduction in beta cell function represents an appropriate beta cell 'rest' in response to a reduction in insulin clearance. Although the present study does not answer the question of whether beta cell function is truly impaired by fat ingestion or is simply resting in response to a reduction in insulin clearance, we favour the view that fat ingestion primarily impairs insulin secretion because of the large body of in vitro work from various groups supporting the concept of reduced GSIS in beta cells exposed in a prolonged fashion to high NEFA concentrations [9] and because of other in vivo studies showing absolute reductions in glucose-stimulated insulin levels after prolonged NEFA elevation [8, 30, 47].

In conclusion, we have demonstrated that continuous oral ingestion of PUFA for $24 \mathrm{~h}$ impairs GSIS, that ingestion of SFA reduces whole-body insulin sensitivity, and that ingestion of MUFA, PUFA and SFA all decrease insulin clearance. In the face of insulin resistance in the SFA study, insulin secretion was not increased, which suggests decreased beta cell function in the SFA study, but we cannot exclude greater impairment of beta cell function with PUFA, as evidenced by the absolute reduction in ISR. These data have important implications for understanding the complex interplay between the nature of dietary fat and whole-body insulin, glucose and lipid dynamics, but we acknowledge that long-term dietary intervention studies are required to determine whether the chronic ingestion of a high-fat diet is implicated in the beta cell failure that characterises the conversion from insulin resistance to type 2 diabetes.

Acknowledgements This work was supported by an operating grant from the Canadian Diabetes Association. C. Xiao is funded by a New Emerging Team grant from the Canadian Institutes of Health Research. G. F. Lewis holds a Canada Research Chair in Diabetes and is a Career Investigator of the Heart and Stroke Foundation of Canada. A. Carpentier is a new investigator of the Canadian Institutes of Health Research. We would like to thank A. Kuksis (University of Toronto) for performing the fatty acid compositional analyses for this study.

\section{References}

1. Taylor SI, Accili D, Imai Y (1994) Insulin resistance or insulin deficiency. Which is the primary cause of NIDDM? Diabetes 43:735-740
2. DeFronzo RA (1992) Pathogenesis of type 2 (non-insulin dependent) diabetes mellitus: a balanced overview. Diabetologia 35:389-397

3. Porte D Jr (1991) Banting lecture 1990. Beta-cells in type II diabetes mellitus. Diabetes 40:166-180

4. Polonsky KS (1995) Lilly Lecture 1994. The beta-cell in diabetes: from molecular genetics to clinical research. Diabetes 44:705-717

5. Stein DT, Esser V, Stevenson BE et al (1996) Essentiality of circulating fatty acids for glucose-stimulated insulin secretion in the fasted rat. J Clin Invest 97:2728-2735

6. Grill V, Qvigstad E (2000) Fatty acids and insulin secretion. Br J Nutr 83 (Suppl 1):S79-S84

7. Lewis GF, Carpentier A, Adeli K, Giacca A (2002) Disordered fat storage and mobilization in the pathogenesis of insulin resistance and type 2 diabetes. Endocr Rev 23:201-229

8. Kashyap S, Belfort R, Gastaldelli A et al (2003) A sustained increase in plasma free fatty acids impairs insulin secretion in nondiabetic subjects genetically predisposed to develop type 2 diabetes. Diabetes 52:2461-2474

9. Prentki M, Joly E, El Assaad W, Roduit R (2002) Malonyl-CoA signaling, lipid partitioning, and glucolipotoxicity: role in betacell adaptation and failure in the etiology of diabetes. Diabetes 51 (Suppl 3):S405-S413

10. Stein DT, Stevenson BE, Chester MW et al (1997) The insulinotropic potency of fatty acids is influenced profoundly by their chain length and degree of saturation. J Clin Invest 100:398-403

11. Beysen C, Karpe F, Fielding BA, Clark A, Levy JC, Frayn KN (2002) Interaction between specific fatty acids, GLP-1 and insulin secretion in humans. Diabetologia 45:1533-1541

12. Brubaker PL, Anini Y (2003) Direct and indirect mechanisms regulating secretion of glucagon-like peptide-1 and glucagonlike peptide-2. Can J Physiol Pharmacol 81:1005-1012

13. Carpentier A, Mittelman SD, Bergman RN, Giacca A, Lewis GF (2000) Prolonged elevation of plasma free fatty acids impairs pancreatic beta-cell function in obese nondiabetic humans but not in individuals with type 2 diabetes. Diabetes 49:399-408

14. American Diabetes Association (2004) Diagnosis and classification of diabetes mellitus. Diabetes Care 27:S5-S10

15. Carpentier A, Mittelman SD, Lamarche B, Bergman RN, Giacca A, Lewis GF (1999) Acute enhancement of insulin secretion by FFA in humans is lost with prolonged FFA elevation. Am J Physiol 276:E1055-E1066

16. Lookene A, Skottova N, Olivecrona G (1994) Interactions of lipoprotein lipase with the active-site inhibitor tetrahydrolipstatin (Orlistat). Eur J Biochem 222:395-403

17. DeFronzo RA, Tobin JD, Andres R (1979) Glucose clamp technique: a method for quantifying insulin secretion and resistance. Am J Physiol 237:E214-E223

18. Van Cauter E, Mestrez F, Sturis J, Polonsky KS (1992) Estimation of insulin secretion rates from C-peptide levels. Comparison of individual and standard kinetic parameters for C-peptide clearance. Diabetes 41:368-377

19. de Almeida IT, Cortez-Pinto H, Fidalgo G, Rodrigues D, Camilo ME (2002) Plasma total and free fatty acids composition in human non-alcoholic steatohepatitis. Clin Nutr 21:219-223

20. Boden G, Chen X, Rosner J, Barton M (1995) Effects of a 48-h fat infusion on insulin secretion and glucose utilization. Diabetes 44:1239-1242

21. Carpentier A, Giacca A, Lewis GF (2001) Effect of increased plasma non-esterified fatty acids (NEFA) on arginine-stimulated insulin secretion in obese humans. Diabetologia 44:1989-1997

22. Carpentier A, Zinman B, Leung N et al (2003) Free fatty acidmediated impairment of glucose-stimulated insulin secretion in nondiabetic Oji-Cree individuals from the Sandy Lake community of Ontario, Canada: a population at very high risk for developing type 2 diabetes. Diabetes 52:1485-1495 
23. Leung N, Sakaue T, Carpentier A, Uffelman K, Giacca A, Lewis GF (2004) Prolonged increase of plasma non-esterified fatty acids fully abolishes the stimulatory effect of 24 hours of moderate hyperglycaemia on insulin sensitivity and pancreatic beta-cell function in obese men. Diabetologia 47:204-213

24. Frankenfield D, Roth-Yousey L, Compher C (2005) Comparison of predictive equations for resting metabolic rate in healthy nonobese and obese adults: a systematic review. J Am Diet Assoc 105:775-789

25. Carpentier A, Patterson BW, Leung N, Lewis GF (2002) Sensitivity to acute insulin-mediated suppression of plasma free fatty acids is not a determinant of fasting VLDL triglyceride secretion in healthy humans. Diabetes 51:1867-1875

26. Carpentier AC, Frisch F, Cyr D et al (2005) On the suppression of plasma nonesterified fatty acids by insulin during enhanced intravascular lipolysis in humans. Am J Physiol Endocrinol Metab 289:E849-E856

27. Warnotte C, Nenquin M, Henquin JC (1999) Unbound rather than total concentration and saturation rather than unsaturation determine the potency of fatty acids on insulin secretion. Mol Cell Endocrinol 153:147-153

28. Zhou YP, Grill VE (1994) Long-term exposure of rat pancreatic islets to fatty acids inhibits glucose-induced insulin secretion and biosynthesis through a glucose fatty acid cycle. J Clin Invest 93:870-876

29. Brun T, Assimacopoulos-Jeannet F, Corkey BE, Prentki M (1997) Long-chain fatty acids inhibit acetyl-CoA carboxylase gene expression in the pancreatic beta-cell line INS-1. Diabetes 46:393-400

30. Mason TM, Goh T, Tchipashvili V et al (1999) Prolonged elevation of plasma free fatty acids desensitizes the insulin secretory response to glucose in vivo in rats. Diabetes 48:524-530

31. Dobbins RL, Szczepaniak LS, Myhill J et al (2002) The composition of dietary fat directly influences glucose-stimulated insulin secretion in rats. Diabetes 51:1825-1833

32. Luan J, Browne PO, Harding AH et al (2001) Evidence for gene-nutrient interaction at the PPARgamma locus. Diabetes 50:686-689

33. Lin Q, Ruuska SE, Shaw NS, Dong D, Noy N (1999) Ligand selectivity of the peroxisome proliferator-activated receptor alpha. Biochemistry 38:185-190

34. Warnotte C, Nenquin M, Henquin JC (1999) Unbound rather than total concentration and saturation rather than unsaturation determine the potency of fatty acids on insulin secretion. Mol Cell Endocrinol 153:147-153
35. Chan CB, MacDonald PE, Saleh MC, Johns DC, Marban E, Wheeler MB (1999) Overexpression of uncoupling protein 2 inhibits glucose-stimulated insulin secretion from rat islets. Diabetes 48:1482-1486

36. Pamplona R, Portero-Otin M, Riba D et al (1998) Mitochondrial membrane peroxidizability index is inversely related to maximum life span in mammals. J Lipid Res 39:1989-1994

37. Evans JL, Goldfine ID, Maddux BA, Grodsky GM (2002) Oxidative stress and stress-activated signaling pathways: a unifying hypothesis of type 2 diabetes. Endocr Rev 23:599-622

38. Borkman M, Storlien LH, Pan DA, Jenkins AB, Chisholm DJ, Campbell LV (1993) The relation between insulin sensitivity and the fatty-acid composition of skeletal-muscle phospholipids. N Engl J Med 328:238-244

39. Storlien LH, Jenkins AB, Chisholm DJ, Pascoe WS, Khouri S, Kraegen EW (1991) Influence of dietary fat composition on development of insulin resistance in rats. Relationship to muscle triglyceride and omega-3 fatty acids in muscle phospholipid. Diabetes 40:280-289

40. Vessby B, Unsitupa M, Hermansen K et al (2001) Substituting dietary saturated for monounsaturated fat impairs insulin sensitivity in healthy men and women: the KANWU Study. Diabetologia 44:312-319

41. Bergman RN, Phillips LS, Cobelli C (1981) Physiologic evaluation of factors controlling glucose tolerance in man: measurement of insulin sensitivity and beta-cell glucose sensitivity from the response to intravenous glucose. J Clin Invest 68:1456-1467

42. Drucker DJ (2003) Enhancing incretin action for the treatment of type 2 diabetes. Diabetes Care 26:2929-2940

43. Rocca AS, LaGreca J, Kalitsky J, Brubaker PL (2001) Monounsaturated fatty acid diets improve glycemic tolerance through increased secretion of glucagon-like peptide-1. Endocrinology 142:1148-1155

44. Xiao Q, Boushey RP, Drucker DJ, Brubaker PL (1999) Secretion of the intestinotropic hormone glucagon-like peptide 2 is differentially regulated by nutrients in humans. Gastroenterology 117:99-105

45. Wiesenthal SR, Sandhu H, McCall RH et al (1999) Free fatty acids impair hepatic insulin extraction in vivo. Diabetes 48:766-774

46. Bergman RN (2002) Pathogenesis and prediction of diabetes mellitus: lessons from integrative physiology. Mt Sinai J Med 69:280-290

47. Paolisso G, Gambardella A, Amato L et al (1995) Opposite effects of short- and long-term fatty acid infusion on insulin secretion in healthy subjects. Diabetologia 38:1295-1299 